\title{
"EFFECT OF THE NUMBER OF SUBSTITUENTS ON THE BEHAVIOR OF MODIFIED ELECTRODES WITH COBALT PORPHYRINS SUBSTITUTED WITH A DIFFERENT NUMBERS OF BIS(METHOXYPHENYL) GROUPS TOWARD THE OXIDATION OF SULFITE."
}

\author{
W. CHEUQUEPÁN $N^{1}$, D. VILLAGRA2, M.I. AZÓCAR', G. RAMÍREZ ${ }^{3}$, Y.Y. CHEN ${ }^{1}$, B. MATSUHIRO', L. \\ MENDOZA', M. ISAACS ${ }^{4}$, M.J. AGUIRRE ${ }^{I^{*}}$
}

\begin{abstract}
${ }^{\text {I}}$ Departamento de Química de Los Materiales, Facultad de Química y Biología, Universidad de Santiago de Chile, Av. B. O'Higgins 3363, Santiago, Chile. ${ }^{2}$ Departamento de Química, Facultad de Ciencias, Universidad de Tarapacá, Av. General Velásquez 1775, Arica, Chile. ${ }^{3}$ Departamento de Química Inorgánica, Facultad de Química, Pontificia Universidad Católica de Chile, Av. Vicuña Mackenna 4860, Casilla 306, Correo 22, Santiago, Chile. ${ }^{4}$ Departamento de Química, Facultad de Ciencias, Universidad de Chile, Las Palmeras 3425, Santiago, Chile.
\end{abstract}

(Received: November 10, 2009 - Accepted: March 16, 2010)

\begin{abstract}
In this study, we compared four glassy carbon electrodes modified with adsorbed porphyrins of cobalt containing one, two, three, or four bis(methoxyphenyl) groups as substituents of the ligand. The aim of this work was to determine the effect of these donating groups on the electrocatalyst behavior of the modified electrodes for the reduction or oxidation of sulfite in water or in mixtures of $12 \%$ ethanol in water $(\mathrm{v} / \mathrm{v})$ at different pHs. The results showed that the modified electrodes are not catalytic toward the electro-reduction of sulfite in the whole range of $\mathrm{pH}$ studied (2-12). However, all the electrodes showed a catalytic toward the oxidation of sulfite at basic pHs. We found that the best catalytic system was the four-substituted porphyrin modified electrode at $\mathrm{pH} 9.8$. This system performed well as an amperometric sensor for sulfite in ethanol-water mixtures and in aqueous solutions at the same pH. When the calibration curve was carried out by cyclic voltammetry, a detection limit of $0.10 \mathrm{mg} \mathrm{L}^{-1}$ for the four-substituted cobalt porphyrin modified electrode in water and in ethanol-water mixtures was found.
\end{abstract}

Keywords: cobalt porphyrins, modified electrodes, sulfite electrocatalysis, amperometric sensor

\section{INTRODUCTION}

The detection and remediation of sulfur-containing species has drawn the attention of chemical and biological researchers over the last few decades [1-5]. Sulfite is used as an antioxidant and antiseptic agent in the food and beverage industries. However, sulfite content should be strictly limited due to its potential toxicity $[6,7]$. Several analytical methods and procedures can be used to detect sulfite [8-17]. Electrochemical techniques have also been explored for sulfite detection [18-23]. To our best knowledge, the main advantage is the fast response and the low cost of the electrochemical methods compared to other methods [13, 16, 19, 20, 24-35]. On the other hand, the detection limit for sulfite analysis varies on the method used. As example, the modified para-rosanilineformaldehyde method [36] permits to detect sulfite with a detection limit of $7.1 \cdot 10^{-5} \mathrm{M}$. On the other hand, by polarography the detection limit is $2 \cdot 10^{-6} \mathrm{M}$ [37]. Using a sulfite oxidase biosensor [38] the detection limit is $1.6 \cdot 10^{-3} \mathrm{M}$. For sequential injection-flow injection spectrophotometrical determination of sulfite the detection limit of $0.3 \mathrm{mgL}-1$ [39]. Porphyrins and other related macrocycles have been used as catalysts in many reactions of environmental and analytical significance [40-45]. These complexes exhibit catalytic activity either in the homogenous phase or immobilized onto electrode surfaces.

The purpose of this work is to evaluate the electrocatalytic activity of glassy carbon electrodes modified by a series of substituted Co(II) porphyrins toward sulfite oxidation in solutions of water and ethanol in water. The aim is to determinate the effect of the number of donor substituent in the electrocatalytic behaviour of four modified electrodes with Co-porphyrins.

\section{EXPERIMENTAL}

Reagents: Meso-Veratrylporphyrins (monoaryl, diaryl, triaryl, and tetraaryl) were synthesized according to reference [46]. The metallations of the complexes were done following the general procedure described in the literature $[47,48]$. All reagents and solvents used in the preparation of the complexes were purchased from Aldrich or Merck (p.a.) and used without further purification. High purity $(99.999 \%)$ nitrogen (AGA) was used in the electrochemical experiments. Water was deionized and double distilled. All the solutions were used freshly. Sulfite solutions were prepared by weight of $\mathrm{Na}_{2} \mathrm{SO}_{3}$ in a deaerated $12 \% \mathrm{v} / \mathrm{v}$ ethanol-water mixture or water containing 0.1 $\mathrm{M} \cdot \mathrm{L}^{-1} \mathrm{NaCl}$. The $\mathrm{pH}$ was adjusted by adding $\mathrm{NaOH}$ or $\mathrm{HCl}$ to the solution. Electrodes: Glassy carbon (CHI 104) (geometrical exposed area: $12.6 \mathrm{~mm}^{2}$ ) was polished first with sandpaper and then with an alumina slurry of $0.3 \mathrm{~mm}$ particles (Struers OP-NAP) on polishing cloth with water as lubricant, then sonicated for $2 \mathrm{~min}$. and rinsed with pure water. The electrode has some little bits or defects for enhancing the adsorption of the porphyrin. $\mathrm{An} \mathrm{Ag} / \mathrm{AgCl}$
(CHI 111) electrode was used as reference and Pt wire as counter electrode. The working electrode was modified with the porphyrin solution by placing a drop of solution $(1 \mathrm{mM})$ in $\mathrm{CH}_{2} \mathrm{Cl}_{2}$ (dichloromethane) on the glassy carbon surface. After 45 minutes the electrode was rinsed with $\mathrm{CH}_{2} \mathrm{Cl}_{2}$, ethanol and deionized, double-distilled water. The modification of the electrode was tested by comparison of the voltammetric response of the bare glassy carbon and the treated electrode. The voltammetric response of the modified electrode shows two semi reversible couples that do not appear in the case of the bare glassy carbon.

Electrochemical measurements: The voltammetric responses were done in deaerated solutions in a conventional three compartment Pyrex glass cell and using A 640C CHI Electrochemical Analyzer Potentiostat. A HI8424 HANNA $\mathrm{pH}$ meter was used to measure the $\mathrm{pH}$ of the solutions. The products from electrolysis experiments were detected using a HPLC Chromatograph Waters 1515 isocratic HPLC pump coupled with Waters 432 conductivity detector and 428 refractive index detector. UV-visible spectra were obtained using quartz cuvettes (1 cm length) in a Specord Analyticjena S 100 spectrometer.

\section{RESULTS AND DISCUSSION}

Figure 1 shows the structures of the four porphyrins employed in this study. The synthesis of these porphyrin, ligands were previously reported [46]. The metallization of each compound gave practically the same yield of approximately $75 \%$, regardless of the substituents.
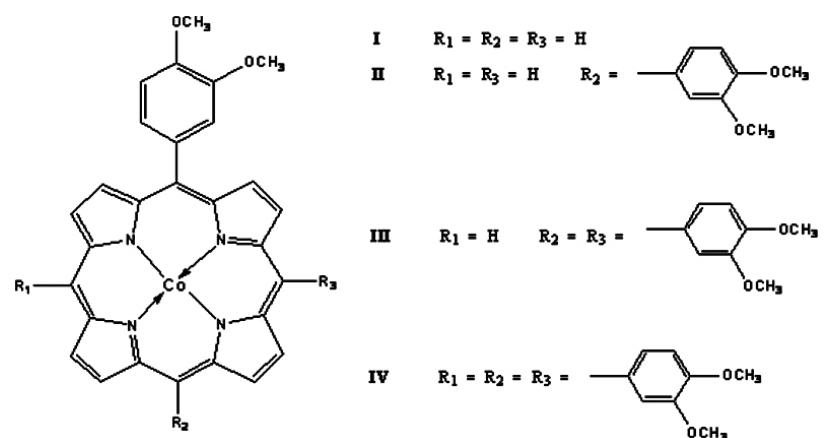

Figure 1. Molecular structures of the porphyrins employed in this study. 
As shown in Fig. 1, the porphyrins are labelled as I, II, III and IV depending on the number of ligand substituents. We also use the labels I-Co, II-Co, IIICo and IV-Co or I-H, II-H, III-H and IV-H to indicate the metallated complex or the free ligand, respectively. The substituents affect the electron density of the metal center as well as the difference between the HOMO and LUMO of the principal electronic transition bands ( $\mathrm{Q}$ and Soret bands) of the ligand. The Soret bands of the free ligand and those of the metallated complexes shift to higher wavelengths when the substituent number changes from 1 to 4 , indicating an increase in the conjugation of the azamacrocycle caused by the substituents. The increase in conjugation suggests, interestingly, that torsion of the phenyl substituents occurs in order to permit a certain degree of planarity with the core of the macrocycle $[47,48]$.

Figure 2 shows the variation of the maximum of the Soret band as a function of the number of substituents of the peripheral ligand.

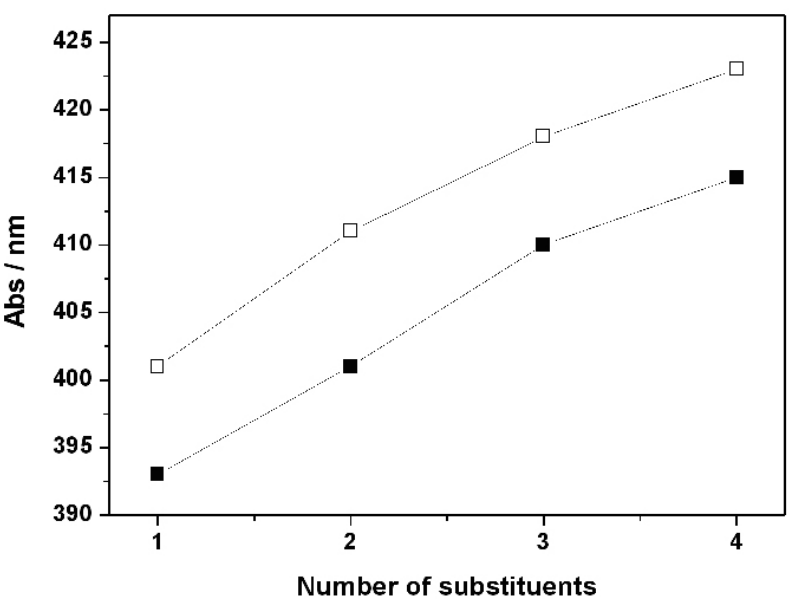

Figure 2. Maximum of the Soret band as function of number of substituents of the peripheral ligand. Solid square: Co-complexes. Open square: free ligands. Data was taken from the UV-Vis spectra of the compounds in $\mathrm{CH}_{2} \mathrm{Cl}_{2}$

Figure 2 indicates that, as substituents are added, they become conjugated with the core of the azamacrocycles. These changes are also reflected on the voltammetric profiles of the ligands and complexes. All the complexes show two semi-reversible waves corresponding to $\mathrm{Co}(\mathrm{III})$ and $\mathrm{Co}(\mathrm{II})$ and a ligand process labeled peaks 1 and 2 respectively (see Figure 3) $[49,50]$. Table I gives the potential of the cathodic (Epc) and the anodic peak (Epa) of the four complexes adsorbed on glassy carbon and measured in a $0.5 \mathrm{M} \mathrm{NaCl}(\mathrm{pH} 9)$ solution at $50 \mathrm{mVs}^{-1}$. The assignment of the redox processes are made based in literature $[49,50]$.

Table I: Potential corresponding to the maximum of the redox process $\mathrm{Co}(\mathrm{III}) / \mathrm{Co}(\mathrm{II})$ (peak 1 ) and the ligand $\mathrm{L}^{-1 / 2}$ (peak 2 ) of the four complexes. The data were obtained from the voltammetric profiles of the complexes adsorbed on glassy carbon and registered at $50 \mathrm{mVs}^{-1}$ in $0.5 \mathrm{M} \mathrm{NaCl} \mathrm{pH} 9.85$ electrolyte. Epa: anodic potential peak. Epc: cathodic potential peak

\begin{tabular}{|c|c|c|c|c|}
\hline & $\begin{array}{c}\text { Epa 1/V vs. } \\
\mathrm{Ag} / \mathrm{AgCl}\end{array}$ & $\begin{array}{c}\text { Epc 1/V vs. } \\
\mathrm{Ag} / \mathrm{AgCl}\end{array}$ & $\begin{array}{c}\text { Epa 2/V } \\
\text { vs. Ag/AgCl }\end{array}$ & $\begin{array}{c}\text { Epc 2/ } \\
\text { V vs. Ag/ } \\
\mathrm{AgCl}\end{array}$ \\
\hline I-Co & 0.21 & 0.11 & 0.50 & 0.40 \\
\hline II-Co & 0.20 & 0.10 & 0.49 & 0.39 \\
\hline III-Co & 0.19 & 0.09 & 0.48 & 0.38 \\
\hline IV-Co & 0.18 & 0.08 & 0.47 & 0.37 \\
\hline
\end{tabular}

Figure 3 shows a shift in both peak potentials ( 1 and 2 ) depending on the number of substituents in the molecule. In fact, when the number of substituents increases, the potential values of the anodic peaks 1 and 2 are shifted toward more negative potential values, indicating that the more highly substituted complexes are more easily oxidized. Also, the cathodic peaks become more negative as the number of substituents changes from one to four [51-53]. The more negative values of the potentials of both, the anodic and cathodic peak of the metal and the ligand redox processes indicates that the species is more negatively charged compared to the others. For that reason, is easily to be oxidized (more negative value of the anodic peaks) and more difficult to be reduced (more negative values of the cathodic peaks). These facts are attributed to the more negative density of the redox sites, the metal center and the ligand skeleton due to the donating effect of the substituents. This result confirms that the groups are electronically connected with the metal center and with the porphyrinic ligand. On the other hand, the current is different for each modified electrode. However, if the number of molecules deposited on the surface are "measured" in terms of the current or the charge of the peak 1, IV-Co, III-Co and II-Co are practically in the same quantity. The capacitive current is higher as a function of the number of substituents probably due to the formation of more disordered layers on the surface.

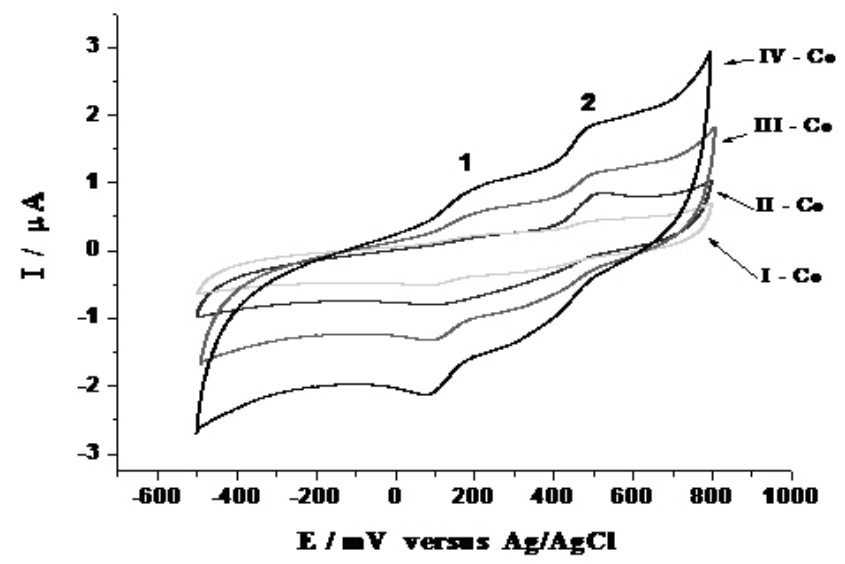

Figure 3. Potentiodynamic profiles of the four modified electrodes in the solution. $\mathrm{pH}$ of the aqueous solution: 9.85. Scan rate: $50 \mathrm{mVs}^{-1}$. Peak 1 corresponds to $\mathrm{Co}(\mathrm{II}) / \mathrm{Co}(\mathrm{III})$ transition and peak 2 corresponds to a redox process centered in the ligand.

Finally, we demonstrate that only the tetrasubsituted porphyrin-modified electrode acts as electrocatalyst compared to the bare glassy carbon for the oxidation of sulfite. Considering the reduction process, we studied the behavior in aqueous and mixture ehanol/water solutions at different $\mathrm{pH}$ values ranging from 2 to 12 . In all four cases, the modified electrodes were unable to catalyze the reaction. In the case of the oxidation, the same $\mathrm{pHs}$ were studied and the four modified electrodes were catalytic at basic $\mathrm{pH}$, catalyzing the oxidation of sulfite to sulfate. It was not detected dithionate as a product after one hourelectrolysis experiment. After obtaining this result, we carried out a more detailed study of $\mathrm{pH}$ to determine that the best response is obtained at $\mathrm{pH} 9.85$. Figure 4 shows the electrocatalytic response of the four modified electrodes to the oxidation of sulfite compared to the bare glassy carbon.

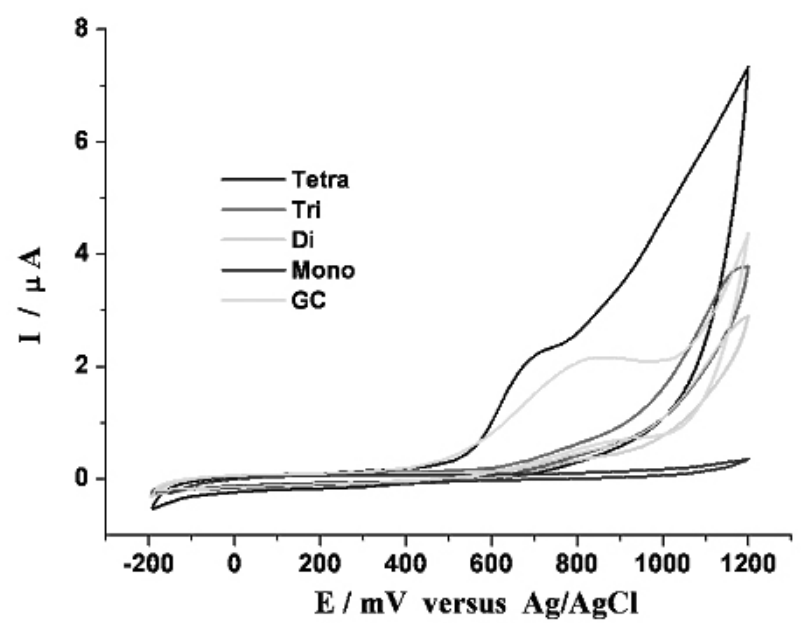

Figure 4. Potentiodynamic profiles of the four modified electrodes and the bare glassy carbon for the oxidation of sulfite $(100 \mathrm{ppm}) . \mathrm{pH}$ of the aqueous solution: 9.85. Scan rate: $5 \mathrm{mVs}^{-1}$. 
Clear differences in the potential required for the reaction are seen among the four systems. The four-substituted porphyrin shows a current wave that starts at more negative potentials compared to the other modified electrodes. The potential of the foot of the wave of the four-substituted system is practically the same of the glassy carbon electrode. Then, the catalysis observed is only in terms of current considering the stability and the unique reaction product obtained with the modified electrode. On the other hand, in all four cases, the current was proportional of the square root of the scan rate, indicating diffusion control of the process (data not shown). As expected, the best modified electrode is that corresponding to the more oxidizable porphyrin (IV-Co), indicating that the porphyrin acts as a redox mediator of the sulfite oxidation. In fact, the onset for the oxidation processes are concordant with the onset of peak 2 (not shown), indicating that the oxidized ligand promotes the oxidation of sulfite. Interestingly, the redox active site is not the metal center. However, the free ligands are not catalytic compared to the metallated ones. The role of the metal in the case of the Co-porphyrins is to change the electronic density of the ligand due to a significant metal dp-porphyrin ring $\mathrm{p}^{*}$ interaction (metal to ligand p-backbonding) [51, 52]. A similar result was obtained by us using $\mathrm{Cu}$-porphyrin/modified electrodes toward the same reaction [53]. In this case, as in the Co-porphyrin case, a possible mechanism can be described as follows:

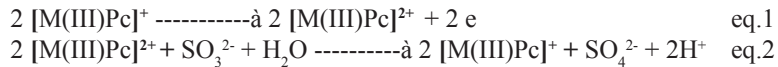

From another point of view, all the systems promote the oxidation of sulfite to sulfate (measured after one hour of electrolysis at $650 \mathrm{mV}$ ) and show a linear relationship between current and concentration with $\mathrm{R}=0.9989$. The detection limit of the most sensitive modified electrode is $0.10 \mathrm{mg} \mathrm{L}^{-1}$.

Finally, the modified electrodes were shown to be stable at least for one week and for 50 measurements in the absence of sulfite. When sulfite is present in the solution, the profile change after the first oxidation but maintain its behavior for the second and subsequent oxidations (see Figure 5).

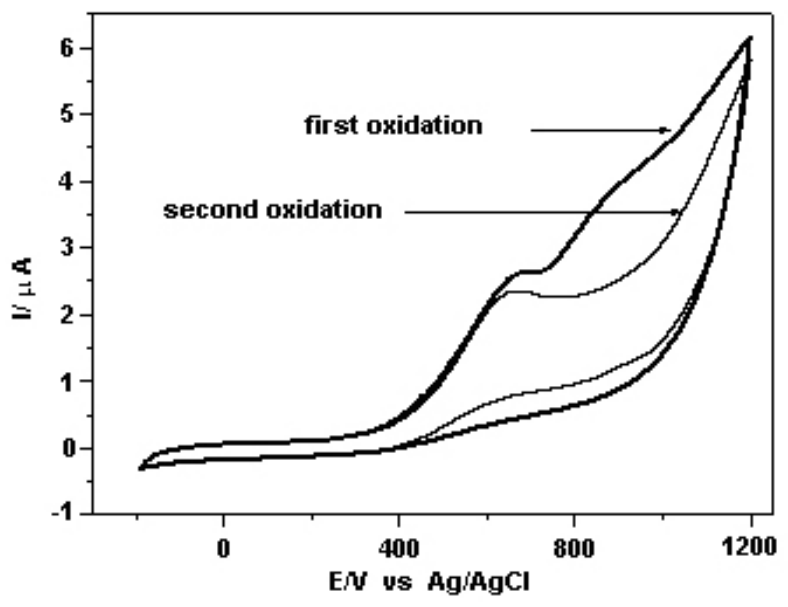

Figure 5. Potentiodinamic profile of the IV-Co-modified electrode for the oxidation of sulfite (100 ppm). $\mathrm{pH}$ of the aqueous solution: 9.85 . Scan rate: 5 $\mathrm{mVs}^{-1}$. First and second oxidation profiles.

It is interesting to note that the enhancement in the current for the four-substituted modified electrode is not an artifact due to a difference in concentration or number of species on the electrode surface because the second and subsequent oxidations show only the current for potentials more positive than $0.8 \mathrm{~V}$ where the others modified electrodes show in the first scan, practically the same current. On the other hand, as mentioned above, the charge of the peak 1 for the IV-Co, III-Co and II-Co systems are quite similar indicating the same quantity of active porphyrins. Lose in the activity after the second cycle is due to a concentration effect because the solution is not agitated. If $\mathrm{N}_{2}$ is bubbled between each measured, the profile of the first scan maintains.

\section{CONCLUSIONS}

The four modified electrodes promote the oxidation of sulfite to sulfate in water or in mixtures of ethanol and water. Of the four electrodes studied the unique that is more catalytic that the bare glassy carbon is that one modified with the porphyrin with four substituents because it is more oxidizable than the others and catalyzes the reaction as a redox mediator. A possible mechanism involves the ligand as the active site and two transferred electrons. It is not common that the ligand and not the metal acts as the active site but it is not an unique example. Notably, the active site is not the metal center, although the non-metallated porphyrins are not catalytic. This finding is explained in terms of a change in the electronic density of the ligand due to $\pi \mathrm{b}$ Surprising; the modified electrodes cannot catalyze the reduction of sulfite over the whole range of $\mathrm{pH}$ studied. backbonding between the metal and the porphyrin ring.

The four-modified electrode is stable, acts as an amperometric sensor of sulfite with a detection limit of $0.10 \mathrm{mg} \mathrm{L}^{-1}$.

\section{ACKNOWLEDGEMENTS}

Financial support from ACT No 24 Conicyt/World Bank project, DicytUsach, Fondecyt Project 11075048, PCI projects A/6129/06 and A/012666/07 are acknowledged. MCG is thankful to Caja Canarias for a Ph.D. Grant.

\section{REFERENCES}

1. C. Lion, L.D. Conceicao, H. Sayang, C.R. Acad. Sci. Ser.II.C. 2, 57, (1999).

2. M. Ali, M. McDermott, Tetrahedron Lett. 43, 6271, (2002).

3. J. Farkas, Technologie a Biochemie Vina, SNTL/ALFA, Prague, (1980).

4. T. Stevenson, Svetová Encyklopedia Vin, Ikar, Bratislava, (1999).

5. C.E. Butzke, Am. J. Enol. Viticult. 53, 163,(2002)

6. B.L.Wedzicha, Chem. Br.27, 1030, (1991)

7. R. Walker, Food Addit. Contam 2, 5, (1985)

8. J. Pavon, J. Plaza, E.Alonso, A. de Torres, M. Pozo, A. Molina, Quim. Anal. , 16, 235, (1997)

9. J. Sádecká, J. Polonský, J. Chromatogr. A. 834, 401. (1999)

10. X.-F.Yang, X.-Q. Guo, Y.-B. Zhao, Anal. Chim. Acta. 456, 121, (2002)

11. W. Qin, Z. Zhang, C. Zhang, Anal. Chim. Acta. 361, 201, (1998)

12. R.L. Bonifacio, N. Coichev, Anal. Chim. Acta. 517, 125, (2004)

13. L.G. Decnopweever, J.C. Kraak, Anal. Chim. Acta. 337, 125, (1997)

14. I.V. Puyayeva, N.L. Yogorova, L.P. Experiandova, A.B. Blank, Anal. Chim. Acta. 357, 239, (1997)

15. K. Sonne, P.K. Dasgupta, Anal. Chem., 63, 427, (1991)

16. X. Su, W. Wei, L. Nie, S. Yao, Analyst, 123, 221, (1998)

17. G. Monnier, S. Williams, Analyst. 95, 119, (1972)

18. M. Lucero, G. Ramírez, A. Riquelme, I. Azocar, M. Isaacs, F.Armijo, J. Förster, E. Trollund, D. Lexa, M. J. Aguirre, J. Mol. Catal. A: Chem., $221,71,(2004)$

19. Z.-N. Gao, J.-F. Ma, W.-Y. Lu, Appl. Organometal. Chem. 19, 1149, (2005)

20. T. García, E. Casero, E. Lorenzo, F. Pariente, Sens. Actuat. B. 106, 803, (2005)

21. I. Rubinstein, A.J. Bard, J. Am. Chem. Soc. 102, 6641, (1980)

22. S.-M. Chen, J-W. Liu, R. Thangamuthu, Electroanal. 19, 1429, (2007)

23. S.-M. Chen, M.-H.Wu, R. Thangamuthu, Electroanal. 20, 178, (2008)

24. J. Bartoli, M. Escalada, C. J. Jourguera, J. Alonso, Anal. Chem. 63, 2532, (1991)

25. H. Meng, F. W. Wu, Z. K. He, Y. E. Zeng, Talanta, 48, 571, (1999)

26. Z. K. He, F. W. Wu, H. Meng, Y. E. Zeng, Analyst, 123, 2109, (1998)

27. R. Carballo, V. C. Dall'Orto, A. L. Balbo, I. Rezano, Sens. Actuat. B, 88,155 . (2003)

28. M.H. Pournaghi-Azar, R.E. Sabzi, Electroanalysis, 16, 860, (2004)

29. M.H. Pournaghi-Azar, M. Hydarpour, H. Dastangoo, Anal. Chim. Acta, 497,133, (2003)

30. I.G. Casella, R. Marchese, Anal. Chim. Acta, 311, 199, (1995)

31. S.-M. Chen, Inorg. Chim. Acta, 249, 143, (1996)

32. R. Ojani, J.B. Raoof, A. Alinezhad, Electroanalysis, 14,1197, (2002)

33. S.-M. Chen, S.-W. Chiu, Electrochim. Acta., 45, 4399, (2000)

34. K.Araki, L. Angenes, C. M. N. Azevedo, H. E. Toma, J. Electroanal. Chem., 97, 205, (1995)

35. N. Rea, B. loock, D. Lexa, Inorg. Chim. Acta, 312, 53, (2001)

36. Y. Li, M. Zhao, Food Control, 17, 975, (2006)

37. Ü. Yilmaz, G. Somer, Anal. Chim. Acta, 603, 30, (2007).

38. E. Dinckaya, M. Sezgintürk, E. Akyilmaz, F. Ertas, Food Chem., 101, 1540, (2007)

39. P. Tzanavaras, E. Thiakouli, D. Themelis, Talanta, 77, 1614, (2009).

40. X. Li, Y. Fu, C. Sun, Electroanal. 15, 1707, (2003) 
41. M. Isaacs, J. Canales, M. Aguirre, G. Estíu, F. Caruso, G. Ferraudi, J. Costamagna, Inorg. Chim. Acta, 339, 224, (2002)

42. M. Isaacs, F. Armijo, G. Ramírez, E. Trollund, S. Biaggio, J. Costamagna, M. J. Aguirre. Mol. Cat. A: Chem., 229, 249, (2005)

43. Rita C.S. Luza, Flavio S. Damos, Auro A. Tanaka, Lauro T. Kubota, Yoshitaka Gushikema, Talanta, 76, 1097, (2008)

44. Ildemar Mayer, Henrique E. Toma, Koiti Araki, J. Electroanal. Chem. 590 111 (2006)

45. Karolien De Wael Annemie Adriaens Electrochim. Acta 53, 2355 (2008)

46. I. Azócar, F. Isaacs, J. Guerrero, W. Dehaen, M.J. Aguirre, Synth. Commun, 37, 2001, (2007)

47. Y. Terazono, B.O. Patrick, D. H. Dolphin, Inorg. Chim. Acta, 346, 265, (2003)
48. G. Cornejo, G. Ramírez, M. Villagrán, J. Costamagna,; E. Trollund,; M.J. Aguirre, J. Chil. Chem. Soc.48, 49, (2003)

49. K.M. Kadish, K.M. Smith, R. Guilard, (Eds) The Porphyrins Handbook, Vol.8, Acad. Press, USA, (2000).

50. H. Liu, L. Zhang, J. Zhang, D. Ghosha, J. Jung, B. W. Downing, E. Whittemore, J. Power Sources, 161, 743, (2006)

51. D.F. Marsh, L.M. Mink, J. Chem. Educ. 73, 1188, (1996)

52. M. Gouterman, The Porphyrins, Vol 3, Chapter I. D. Dolphin E., Academic, New York, (1978).

53. P. Bravo, Y-Y. Chen, G. Ramírez, M.J. Canales, B. Matsuhiro, L. Mendoza, M. García, M.C. Arévalo, M.J. Aguirre, Collect. Czech. Chem. Commun., 74, 545, (2009). 